\title{
A LITERATURA COMO ANTROPOLOGIA ESPECULATIVA ${ }^{1}$
}

\section{LITERATURE AS SPECULATIVE ANTHROPOLOGY}

\author{
Alexandre Nodari ${ }^{2}$
}

RESUMO: Se décadas atrás, Lyotard identificou a crise de legitimação política e do conhecimento de então como a crise dos grandes relatos, talvez se possa dizer que a crise atual é uma crise do grande Relator: a crise das humanidades seria, assim, parte mais geral da crise do Humano. Diante do Antropoceno, as ciências do homem (as antropologias) têm como um dos seus desafios converterem-se em humanidades, isto é, especular sobre as definições de homem e mundo, descobrindo outras humanidades e mundos. Aqui, a literatura, entendida a partir de Juan José Saer como uma "antropologia especulativa", pode revelar-se uma linha de fuga: diante do contingenciamento econômico das humanidades, ela apresenta a contingência ecológica desse modelo de mundo.

PALAVRAS-CHAVE: Antropologia. Literatura. Antropoceno. Catástrofe ambiental. Especulação.

\begin{abstract}
Decades ago, Lyotard argued that the political and scientific legitimation crisis consisted in a crisis of narratives. In this fashion, it may be said that our current crisis is a narrator crisis: the humanities crisis could therefore be understood as part of the more comprehensive Human crisis. Faced with the Anthropocene, human sciences (the anthropologies) endure the challenge of transforming themselves into humanities, namely, speculate on the definitions of man and world, discovering other humanities and worlds. In such task, literature, understood as a "speculative anthropology" (Juan José Saer), can reveal itself as an escape line (line of flight), presenting the ecological contingency of our world.
\end{abstract}

KEYWORDS: Anthropology. Literature. Anthropocene. Ecological catastrophe. Speculation.

\footnotetext{
${ }^{1}$ Uma versão preliminar desse texto foi apresentada na Semana Acadêmica de Filosofia da UFPR de 2014, durante mesa-redonda sobre "Cosmopolítica", em que participei ao lado de Marco Antonio Valentim e Miguel Carid. Agradeço a eles e aos que participaram do debate, o qual contribuiu muito para o amadurecimento de algumas ideias aqui expostas. Gostaria também de estender o agradecimento àqueles que comentaram e sugeriram alterações ao texto após uma leitura prévia: Guilherme Gontijo Flores, Marcos Matos, Flávia Cera e especialmente Eduardo Viveiros de Castro, pois, como ficará claro, o texto é uma tentativa de pensar a literatura sob o prisma do perspectivismo (algo que também Ana Cernichiaro (2010) tem feito, com outro enfoque).

${ }^{2}$ Professor de Literatura Brasileira e Teoria Literária da UFPR.
} 


\section{A LITERATURA COMO ANTROPOLOGIA ESPECULATIVA}

"Eu antes tinha querido ser os outros para conhecer o que não era eu. Entendi então que eu já tinha sido os outros e isso era fácil. Minha experiência maior seria ser o outro dos outros: e o outro dos outros era eu."

(Clarice Lispector)

"Tudo que é imaginado existe, é e tem"

(Estamira)

INTRODUÇÃO

\section{ANTROPOCENO, OU DA REDUÇÃO DE MUNDOS}

Algumas décadas atrás, instado a fazer um relatório sobre a situação universitária e do conhecimento mais em geral, François Lyotard definiu a condição pós-moderna como a da crise dos "grandes relatos", propondo como linha de fuga ao problema de legitimidade de então - como o de hoje, associado a uma crise econômica e cuja "saída" financeira foi (como está sendo) o ideário (neo-)liberal - a paralogia, um saber e uma prática social abertos às anomalias: "Uma política se delineia", concluía ele, "na qual serão igualmente respeitados o desejo de justiça e o que se relaciona ao desconhecido" (Lyotard, 1990, p.120). Parafraseando Lyotard $^{3}$, poderíamos afirmar que a atual crise - do conhecimento, mas também política, econômica, social, ambiental, civilizacional, em suma, global - é uma crise do grande Relator. Ou seja, a crise das humanidades é parte da crise mais geral do Humano, magnificamente diagnosticada e passada em revista por Déborah Danowski e Eduardo Viveiros de Castro (2014). Diante da atual catástrofe ambiental antropicamente causada, a distinção entre natureza e cultura, que fundamentava a divisão entre ciências naturais e humanas, é colocada em xeque: para usar a formulação já famosa de Dipesh Chakrabarty

\footnotetext{
${ }^{3}$ Sem nos afastarmos completamente de seu pensamento (que, como se sabe, envolve uma investigação do “inumano" - cf., por exemplo, Lyotard, 1997).
} 
(2013), o clima da história e a história do clima entraram em ressonância e passaram a se confundir. Justamente quando o mito do excepcionalismo humano (o mito-projeto de uma humanidade completamente independente da Terra, do homem como ser extra-terrestre - cf. Nodari, 2013) parece finalmente se realizar, e o Homem se converter em autor da natureza, isto é, quando o homem transforma (nega) a natureza a ponto de se autotransformar, modificando completamente as próprias condições de existência, o resultado parece ser o contrário do esperado: como todo autor, a espécie humana está passando a perceber que não tem total poder sobre aquilo que escreve (ou inscreve ou ex-creve sobre e sob a Terra), o que inclui ela mesma e seu destino, tornando-se um agente geológico (natural) que perdeu o controle das consequências de suas ações - o que se tem chamado de "Antropoceno" (Crutzen e Stomer, 2000). Um estudo recente, de Lewis e Maslin $(2015)^{4}$, propôs como marco inicial do Antropoceno o ano de 1610, o ponto mais baixo de um decréscimo de décadas no nível atmosférico de gás carbônico, ocasionado pelo extermínio direto (guerras e massacres) e indireto (pestes e fome) de mais de 50 milhões de ameríndios. A proposta (que poderia também ser o ano de 1492) indica que a uniformização ambiental do mundo como casa do homem moderno ("cosmopolita" ou "universal", esse habitante de shopping centers e hotéis padronizados mundo afora) é indissociável da destruição de formas humanas e não-humanas de vida, ou seja, de um empobrecimento existencial (de possibilidades) prévio: ao contrário do que dizia Heidegger, o homem moderno não cria mundos, ele empobrece o mundo para estandartizá-lo - em um processo que, para usar um fragmento do romance A famosa revista, de Pagu e Geraldo Ferraz, vai do vestuário às emoções e ideias e se consubstancia na "estandardização do homo sapiens."

É nesse cenário que, a meu ver, se situa a crise das ciências humanas, acuadas em duas frentes: por um lado, pelos críticos do modelo desenvolvimentista, na medida em que elas tiveram um papel de legitimação de certo projeto humanista nada isento de responsabilidade na atual crise, devido ao seu universalismo e sua insistência na divisão natureza e cultura, projeto que se revela ecológica e mesmo humanamente insustentável; por outro, pelos partidários desse mesmo modelo, já que muitas vezes se afirmam como contestadoras dele, ao oporem, ao modelo universal do Homem, não só diferentes modos de vida, mas também definições distintas e variadas do que é o próprio humano, a existência e o mundo (ontologias), ou seja, ao afirmarem a multiplicidade de humanidades. Que as ciências do homem (as antropologias) sejam também chamadas de humanidades, no plural, como se seu objeto fosse ao mesmo tempo uno e múltiplo (o homem $e$ as humanidades), parece indicar que elas se situam num ponto de bifurcação - justamente em um momento em que o mundo parece ter se convertido numa grande encruzilhada. Essa encruzilhada (crise) transparece, de outro modo, naquela esfera que por muito tempo foi tida como exclusiva da espécie humana e da qual as ciências do homem seriam as guardiãs: a linguagem. Pois o letramento tendencialmente universal, o uso das letras nos quatro cantos do mundo, parece não levar necessariamente àquilo que em um antigo jargão se chamava de "emancipação", como, aliás, já advertia Claude Lévi-Strauss (1996, p.278), em sua "Lição de escrita". Hoje em dia, apesar de estatísticas que dizem o contrário, se lê cada vez mais em sentido estrito: grande parte da humanidade passa o dia lendo e escrevendo sem parar em seus computadores, na internet, ou seja, vivemos hoje, de fato, em uma República das Letras, ainda que ela não seja exatamente o que os iluministas imaginaram. A internet nos coloca diante do paradoxo da linguagem: por um lado, a profusão de palavras de ordem da ordem, que podem ser vistas nas caixas de comentário dos grandes portais, por outro, o acesso fácil e rápido a textos e informações "menores" que não têm espaço nos grandes veículos da mídia e do sistema literário

\footnotetext{
${ }^{4}$ Agradeço a Idelber Avelar a indicação desse artigo. Amparei-me, no resumo que faço, na análise de Luciano (2015).
} 
estabelecido, o espírito colaborativo; por um lado, a tentativa de controle e censura por meio dos direitos autorais, por outro, a luta pelo direito de acesso, baseado no princípio de que o pensamento não tem dono.

E aqui, justamente nessa bifurcação, talvez se encontre uma linha de fuga das humanidades diante da crise do Humano. Pois não lemos só para dar consistência a esse mundo, sustentá-lo ou entendê-lo (ciência, filosofia, etc.): também lemos para ver que ele não é tão consistente assim, que podemos transformá-lo, que ele é contingente (literatura, manifestos políticos, etc.). A leitura talvez só se torne uma experiência quando há o encontro entre essas duas dimensões - sem tal encontro, facilmente resulta em conformismo tanto de um lado quanto de outro. Mas se a leitura é esse entrecruzamento (fazer o mundo consistir e também desconsisti-lo, dando consistência a outros mundos descobertos), então ela não se reduz à leitura de textos escritos, isto é, à leitura em sentido estrito, mas constitui uma experiência de contato com o mundo e suas diferentes intensidades, uma prática ético-política (ou ecológica) de adquirir uma consistência singular, mas sempre fugidia, no encontro com as multiplicidades, um habitat (sempre precário e finito) no cosmos, ou seja, uma experiência de antropologia e cosmografia, uma antropologia especulativa. Todo mundo lê (o mundo) o tempo todo. É sobre essa experiência que nos deteremos nesse artigo.

\section{ANTROPOLOGIA, OU DOS MUNDOS POSSÍVEIS}

$\mathrm{Na}$ "Introdução à obra de Marcel Mauss", Lévi-Strauss (2003, p.25; grifo do autor) sublinhava a "situação particular das ciências sociais": não só, como nas ciências físicas, "o observador é ele próprio uma parte de sua observação", ou seja, o sujeito da investigação é também parcialmente seu objeto, mas, além disso, também o "caráter intrínseco" do objeto do cientista social possui uma ambiguidade constitutiva: o seu objeto, as sociedades humanas, são "ao mesmo tempo objeto e sujeito". A dificuldade que se coloca é da observação do etnógrafo ter como "parte integrante" a apreensão subjetiva que o nativo tem do objeto (o próprio nativo), ou seja, a observação demanda que o etnógrafo faça tal apreensão também como se a vivesse tal como o indígena a vive. Ou seja, para dar conta de um objeto que é um sujeito, seria preciso que o sujeito da investigação se transformasse ele próprio nesse objeto, que ele se objetivasse como um outro sujeito (ou obliquasse: pois o desafio é manter uma posição transversal, ser ao mesmo tempo e conjuntamente sujeito e objeto, eu-próprio e mimoutro $^{5}$ ). Tal exercício hipotético e ficcional de perspectivismo seria possível, para LéviStrauss (2003, p.27; grifos nossos), porque a partilha entre objetivo e subjetivo é ela mesma subjetiva, isto é, contingente, e por isso o ponto de vista pode ser trocado e transformado (e o que era sujeito passar a ser objeto e vice-versa) - trata-se de uma condição própria a toda subjetividade:

"As milhares de sociedades que existem ou existiram na superfície da terra são
humanas e, por essa razão, delas participamos de forma subjetiva: poderíamos ter
nascido nelas, e podemos portanto buscar compreendê-las como se nelas tivéssemos
nascido. Mas, ao mesmo tempo, seu conjunto, em relação a uma qualquer dentre
elas, atesta a capacidade do sujeito de objetivar-se em proporções praticamente
ilimitadas, pois essa sociedade de referência, que constitui apenas uma ínfima fração
do dado, está sempre exposta, ela própria, a subdividir-se em duas sociedades
diferentes, uma das quais iria juntar-se à massa enorme daquilo que, para a outra, é e
será sempre objeto, e assim por diante indefinidamente. Toda sociedade diferente da
nossa é objeto, todo grupo de nossa própria sociedade, diferente daquele ao qual
pertencemos, é objeto. Mas essa série ilimitada de objetos, que constitui o Objeto da

\footnotetext{
${ }^{5}$ Tenho tentado desenvolver, a partir da experiência literária de Clarice Lispector, a noção de obliquação. Cf. Nodari, 2014, e o artigo “A 'vida oblíqua': o hetairismo ontológico segundo G.H.”, a ser publicado em breve.
} 
etnografia, e que o sujeito deveria arrancar de si dolorosamente se a diversidade das práticas e dos costumes não o pusesse diante de um fracionamento operado de antemão, jamais a cicatrização histórica ou geográfica poderia fazê-lo esquecer (...) que tais objetos procedem dele, e que a análise desses, conduzida da forma mais objetiva, não poderia deixar de reintegrá-los na subjetividade".

Aqui, Lévi-Strauss parece caracterizar a contingência da posição-sujeito, isto é, seu caráter dêitico, não apenas como um fenômeno histórico (ele mesmo contingente), mas propriamente ontológico: a subjetividade não se caracterizaria pela sua capacidade de diferirse de si, de trocar de posição, mas seria tal diferimento. O sujeito só existe havendo o outro, o objeto: "esse fracionamento", diz ele, "não tem limite, a não ser implicar sempre a existência dos dois termos como condição de sua possibilidade" (Lévi-Strauss, 2003, p.27). Ser sujeito é diferir de si. E, de fato, a seguir, argumenta que a subjetivação do outro pode escapar ao perigo de coincidir com a mera projeção de si, e a dessubjetivação, do risco de coincidir com a mera identificação com o outro, pela existência do inconsciente, isto é, pela nãocoincidência do sujeito consigo mesmo, aquele estranho familiar ou familiar estranho do qual, segundo os estoicos, é preciso passar a vida inteira se apropriando: "em última instância, é uma operação do mesmo tipo que, na psicanálise, nos permite reconquistar nosso eu mais estranho e, na investigação etnológica, nos dá acesso ao mais estranho dos outros como um outro nós. Em ambos os casos, é o mesmo problema que se coloca, o de uma comunicação buscada, ora entre um $e u$ subjetivo e um $e u$ objetivante, ora entre um eu objetivo e um outro subjetivado" (Lévi-Strauss, p.29; grifos do autor).

A cisão entre sujeito e objeto, como dizíamos, é subjetiva, mas isso porque ela é ontologicamente interior ao sujeito. É nesse sentido que Patrice Maniglier (2014) irá afirmar, a partir justamente de Lévi-Strauss, que o ser é ser situável em um conjunto de alternativas ou variações de si mesmo; ou, dito de outro modo, o eu-atual (sujeito) é apenas a posição relacional em um conjunto de eus possíveis (objetos) - mudando tal conjunto, modifica-se o eu atual. Por isso, a "capacidade do sujeito de objetivar-se indefinidamente, isto é (sem conseguir jamais abolir-se como sujeito), de projetar no exterior frações sempre decrescentes de si" (Lévi-Strauss: 2003, p.26-27) ${ }^{6}$ implica também transformar-se ontologicamente: descobrir um eu possível é variar a própria posição, o próprio ser. ${ }^{7} \mathrm{E}$ toda descoberta desse tipo é um encontro em que se descobre não (só) o outro, mas a relação com ele, a relação com outro mundo: "Que queremos dizer quando dizemos que temos diante nós Outro, isto é, outro como eu (...)?”, pergunta Ortega y Gasset (1973, p.155): “Isso implica que esse novo ser (...) é um eu, ego, mas, ao mesmo tempo, é outro, alter, é um alter ego. Este conceito de alter egode um eu que não sou eu, mas que é precisamente outro, portanto, não-eu - tem todo o ar de se parecer com um quadrado redondo, protótipo contraditório e impossível". O que o alter ego mostra a mim, a ego, é a existência de "um mundo alheio ao meu, um outro mundo" (Ortega y Gasset, 1973, p.156) no qual sou objeto, no qual o eu é um outro. Como lembra Daniel Heller-Roazen (2010, p.135), segundo a hipótese de Karl Brugmann, "o termo grego ego, assim como seus correlatos no indo-europeu, derivaria de um substantivo neutro $(* e g[h] o m)$, que significaria simplesmente 'aquiedade' (Hierheit), de modo que, originalmente, 'eu' teria o sentido de ser insubstancial de qualquer coisa que fosse indicada como 'aqui', fosse ela animada ou inanimada, humana ou inumana, sua expressão falada ou escrita". Ou seja, o eu, o aqui, o mundo se modifica diante de um novo eu-aqui: não se trata

\footnotetext{
${ }^{6}$ Viveiros de Castro me chamou a atenção para a recíproca: "a capacidade do objeto de assumir frações sempre crescentes de subjetividade, isto é, de subjetivar-se indefinidamente", como ocorre no xamanismo ameríndio, verdadeira "antropologia reversa" para usar o conceito de Roy Wagner (2010). Cf. o artigo de Viveiros de Castro intitulado justamente "Exchanging perspectives: the transformation of objects into subjects in Amerindian ontologies" (2004).

${ }^{7}$ Para uma leitura atual dos efeitos políticos da antropologia entendida desse modo, cf. Hage, 2012.
} 
de relativismo, mas de perspectivismo. O "eu", desse modo, seria um dêitico (o dêitico dos dêiticos, poderíamos dizer), a marcação por excelência da posição locucionaria do mundo de onde se fala ("O cosmos parte do eu", diria Oswald de Andrade): uma perspectiva, mas não a perspectiva sobre o mundo ("mundo-para-um-sujeito"), e sim a perspectiva de um mundo ("mundo-de-um-sujeito"), para retomar uma diferenciação fundamental entre relativismo e perspectivismo de Déborah Danowski e Eduardo Viveiros de Castro (2014, p.33). E já em 1914 Ortega y Gasset (1966, p.321) perguntava "Quando nos abriremos à convicção de que o ser definitivo do mundo não é matéria nem é alma, não é algo de determinado, mas sim uma perspectiva?"

\title{
LITERATURA, OU DOS MUNDOS INEXISTENTES
}

Nas passagens citadas de Lévi-Strauss, grifamos os vários "como se" de que ele lança mão para descrever a objetivação de si no intuito de apontar para certa afinidade estrutural entre antropologia e literatura ${ }^{8}$ que tentaremos desenvolver, a partir de um belíssimo texto devotado à crítica do gênero de "non-fiction", de Juan José Saer. Nele, a ficção parece se situar na mesma encruzilhada entre objetividade e subjetividade. A ficção, segundo Saer (2009, p.2, 4, 2), não se limita a "uma reivindicação do falso", i.e., à elaboração imaginária de um sujeito; tampouco, obviamente, está constrangida pelo critério da veracidade: na ficção, "está presente" o "entrecruzamento crítico entre verdade e falsidade, essa tensão íntima e decisiva (...). O fim da ficção não é estender-se nesse conflito e sim fazer dele sua matéria, modelando-a 'à sua maneira"':

\begin{abstract}
"Não se escreve ficções", continua, "para se esquivar, por imaturidade ou irresponsabilidade, dos rigores que o tratamento da 'verdade' exige, mas justamente para pôr em evidência o caráter complexo da situação, caráter complexo de que o tratamento limitado ao verificável implica uma redução abusiva e um empobrecimento. Ao dar o salto em direção ao inverificável, a ficção multiplica ao infinito as possibilidades de tratamento. Não dá as costas a uma suposta realidade objetiva: muito pelo contrário, mergulha em sua turbulência, desdenhando a atitude ingênua que consiste em pretender saber de antemão como é essa realidade. Não é uma claudicação ante tal ou qual ética da verdade, mas uma busca de uma um pouco menos rudimentar".
\end{abstract}

É como se o mundo verificável objetivamente fosse insuficiente, e o romancista demandasse tratar "o universo à sua maneira", i.e., dotando-o de perspectiva: a ficção "é um tratamento específico do mundo, inseparável do que trata", "uma identidade total com aquilo que trata" - ou seja, toda perspectiva é isomórfica ao (seu) mundo: perspectiva-de-um-mundo. Tal isomorfia talvez seja resultado daquele desvio da linguagem em relação à função comunicativa que atende pelo nome de poeticidade, em que o modo de dizer e o que é dito entram em ressonância: o discurso poético, segundo uma bela definição de Antonio Candido (1992, p.43) a partir de Jackobson, "tanto chama a atenção sobre si que faz esquecer o mundo, tornando-se outro mundo". "Por causa deste aspecto principalíssimo do relato fíctício",

\footnotetext{
${ }^{8}$ Em um livro clássico, Marilyn Strathern (2006, p.31) reflete sobre como "a análise [antropológica]" pode ser tomada "como uma espécie de ficção conveniente ou controlada". Nesse sentido, Viveiros de Castro (2002, p.123) descreveu o seu artigo sobre "Os pronomes cosmológicos e o perspectivismo ameríndio" como "uma experiência de pensamento e um exercício de ficção antropológica. A expressão 'experiência de pensamento' não tem aqui o sentido usual de entrada imaginária na experiência pelo (próprio) pensamento, mas o de entrada no (outro) pensamento pela experiência real: não se trata de imaginar uma experiência, mas de experimentar uma imaginação. A experiência, no caso, é a minha própria, como etnógrafo e como leitor da bibliografia etnológica sobre a Amazônia indígena, e o experimento, uma ficção controlada por essa experiência. Ou seja, a ficção é antropológica, mas sua antropologia não é fictícia.”
} 
conclui, "por causa também de suas intenções, de sua resolução prática, da posição singular de seu autor entre os imperativos de um saber objetivo e as turbulências da subjetividade, podemos definir de um modo global a ficção como uma antropologia especulativa".

De fato, a ficção literária parece se dar pelo mesmo processo de objetivação e subjetivação de que fala Lévi-Strauss: o autor se objetiva, se obliqua em narrador, em personagens, em heterônimos, etc.; e, por sua vez, o leitor se subjetiva naqueles que, num texto literário, dizem eu. Além disso, está em jogo na ficção, como argumenta Milan Kundera (2009, p.46), a exploração de um território novo da existência por meio de "egos imaginários", alter-egos: "o romance não examina a realidade, mas sim a existência. A existência não é o que aconteceu, a existência é o campo das possibilidades humanas, tudo aquilo que o homem pode tornar-se, tudo aquilo de que é capaz. Os romancistas desenham o mapa da existência descobrindo esta ou aquela possibilidade humana". Todavia, ainda que a literatura, desse modo, compartilhe com a antropologia o diferimento absoluto (o princípio da contradição, o não ser-idêntico-ao-ser) como condição ontológica de possibilidade, ela se diferencia desta na medida em que o eu (e seu mundo) que descobre é não apenas possível como também inexistente. A irrealidade característica da ficção e que ela assume, afirma Ortega (1991, p.51), "não existe em nenhum mundo", habita "o outro mundo, o verdadeiramente outro", o "Ultramundo". Portanto, poderíamos dizer que se a antropologia cartografa mundos possíveis, constituindo uma cosmografia comparada das perspectivas do anthropos, aquilo que a literatura cartografa são mundos inexistentes, sendo uma cosmografia comparada das perspectivas extra-mundanas. Todavia, isso não quer dizer que tal descoberta não nos afete: "O personagem não é uma simulação de um ser vivo. É um ser imaginário. Um ego experimental. (...) Dom Quixote é quase impensável como ser vivo. No entanto, em nossa memória, que personagem é mais vivo que ele?", pergunta Kundera (2009, p.38). E que o romance Dom Quixote trate justamente desta contaminação do real pelo ficcional não é um acaso: a ficção é inseparável do que trata, o modo é o modo da ficção - toda literatura é metaliteratura, assim como toda antropologia é meta-antropologia. A "imaginação simpática" que move a ficção segundo uma personagem, Elizabeth Costello, consiste justamente em criar tal relação entre existência e inexistência, pois consiste na experiência descrita como: "think my way into the existence of a being who has never existed" (pensar meu modo de adentrar a existência de um ser que nunca existiu, em uma tradução literal e imperfeita) - adentrar a existência de um ego experimental, por assim dizer. E se isto é possível, se é possível adentrar a existência de um ser que nunca existiu, então também é possível "pensar meu modo de adentrar a existência de um morcego ou um chimpanzé ou uma ostra, de qualquer ser que participe comigo do substrato da vida" (Coetzee, 2004, p.92; tradução modificada). A literatura, portanto, também é, como Lévi-Strauss definira a etnografia, uma "forma experimental e concreta" do "processo ilimitado de objetivação do sujeito". Todavia, na formulação de Costello, a ilimitação desse processo se revela em sua inteireza, indo para além das fronteiras do humano: se a descrição de Lévi-Strauss se fundamenta na equação Sujeito = Anthropos (em sua argumentação, participamos de forma subjetiva de todas as sociedades na Terra - poderíamos ter nascido nelas - porque elas são humanas), a antropologia especulativa proposta por Coetzee especula sobre a antropologia, questionando a imagem da espécie e suas prerrogativas ontológicas sobre a subjetividade. Assim, de certo modo a equação se mantém, mas invertida: Anthropos = Sujeito, ou seja, todos os seres existentes e inexistentes são humanos porque podemos participar de forma subjetiva de sua existência, obliquarmo-nos como se fôssemos eles.

Desse modo, talvez pudéssemos postular para a relação entre literatura e vida uma relação análoga àquela entre o atual e o possível que subjaz à concepção de Lévi-Strauss, e na qual o eu-atual (sujeito) é só uma posição relacional em um conjunto de eus possíveis (objetos), cada um ele próprio atual. Assim, o eu "real", existente, não ficcional, seria também 
apenas uma posição dentre inúmeros eus inexistentes, egos imaginários e experimentais, cada um existente a seu modo. Se o território comum (o que quer dizer: em disputa) da antropologia é a posição-sujeito, o da literatura talvez seja aquele campo ontológico que Alexius Meinong (2008) chamou de "subsistência", a saber, aquela zona existencial indiferente à existência, onde não vige o "privilégio do atual", convivendo o possível e o efetivo, o existente e o inexistente, a zona da "pseudo-existência", do "quase-ser", "extra-ser" ou "ser-fora", em que tudo tem ser, ainda que não tenha o ser em si: dos seres de fícção aos objetos impossíveis, dos grifos aos quadrados redondos (que Ortega equiparava aos alter egos que são os outros sujeitos), passando por aqueles sujeitos e objetos que existem efetivamente. Trata-se de uma espécie de sub-solo da existência que a aduba e transforma, e de onde ela nasce: e, nesse sentido, se o chamado "pacto ficcional" tem algum sentido é o de designar uma espécie de pacto com o diabo ou o gênio maligno de Descartes, pelo qual autor e leitor saem do "deserto do real" e suas regras, e descem às profundezas da existência, desrealizando esse mundo, tirando sua consistência para dar consistência a um mundo acessível pelo texto. Por isso, escrever e ler ficções é alterar-se, mudar a própria posição existencial, re-situar a própria existência diante de uma nova inexistência descoberta. Talvez aqui esteja um dos motivos pelo interesse (intelectual e popular) cada vez maior pela ficção científica: diante da perspectiva catastrófica de fim de mundo, trata-se de tentar adubar o subsolo existencial empobrecido pelo que Luiz Costa Lima (2007) chamou de "controle do imaginário", tentar sair do deserto do real para entrar na "vera dentridade do real" (Joyce, 2014, p.59). Pois a inexistência literária é também uma in-existência: o que não existe também está dentro da existência, constitui o real; é, nas palavras de Clarice Lispector (1998, p.39-40), "inreal".

\section{ANTROPOLOGIA ESPECULATIVA, OU DO ENCONTRO DE MUNDOS}

"Há", afirma Tiago Pinheiro (2014), "uma dimensão da perspectiva que só se dá quando há a passagem de um discurso entre diferentes meios", ou seja, quando a perspectiva é traduzida, transladada, transferida. Essa dimensão talvez constitua o núcleo de toda antropologia, seja ela social seja ela especulativa. Pois a objetivação, o fracionamento do sujeito como objeto, já é um deslocamento desse gênero, em que a perspectiva do sujeito se desdobra: o saber antropológico brota desta dimensão intersticial em que a perspectiva se transfere de um meio (subjetivo) a outro (objetivo). E, nesse sentido, talvez toda antropologia seja especulativa, isto é, imaginária, mas não menos real por isso, pois depende do ser situarse como se fosse outro: o sujeito como se fosse objeto, o possível como se fosse atual, o inexistente como se fosse existente. Tendemos a encarar esse como se enquanto via de mão única: o estabelecimento de uma identificação entre os termos ou de uma postura falsária e embusteira que quer estabelecer uma relação onde esta não existe. Verdade e falsidade, objetividade e subjetividade: justamente as antinomias que, cada qual a seu modo, Saer e Lévi-Strauss quiseram desmontar. Se a obliquação possibilitada pelo como se (pela ficção) possui um estatuto ontológico, se esse entrecruzamento entre eu e outro é real e existe, então ele designa uma via recíproca, de mão dupla, uma ponte entre mundos, em que tanto a identidade quanto a diferença se afirmam ao mesmo tempo e se reconfiguram mutuamente: o princípio da contradição, o terceiro incluído: eu como outro. O essencial nessa fórmula é a modificação dos dois polos (atual e possível, existente e inexistente), a ponte intersticial entre eles em que ambos se dão ao mesmo tempo, entrando em relação, em que mundos (reais e possíveis, reais e imaginários) se chocam e se comparam: por isso, insistamos, toda literatura e antropologia são sempre meta-literatura e meta-antropologia: sujeito e objeto, possível e impossível, existente e inexistente estão constantemente se redefinindo, constantemente postos em jogo, nesses encontros. A ficção (a comparação) não designa a falsidade, mas o encontro ontológico entre modos - entre atual e possível, existente e inexistente - em que 
estes se redefinem reciprocamente. É um modo dos modos. Nesse sentido, ao definir a ficção na fórmula paradoxal da "irrealidade como tal", Ortega y Gasset $(1991$, p.39) irá precisar que se trata de "uma realidade ambivalente que consiste em duas realidades", em que o que existe é o "o ser como". A antropologia especulativa é o saber desse como-ser, ou melhor, a dimensão da perspectiva desse como-ser. Portanto, a descoberta de um mundo pela antropologia especulativa não torna existente um mundo inexistente; torna existente uma relação antes inexistente (mas subsistente, que sempre foi possível) entre dois mundos, faz estes colidirem, se encontrarem; e faz o explorador redescobrir a si mesmo, isto é, mudar de perspectiva, mudar $a$ perspectiva. A perspectiva da antropologia especulativa, assim, é a que deriva desse encontro - não é a perspectiva de um mundo ou de outro, mas a de sua tradução recíproca: uma entre-perspectiva, uma perspectiva caleidoscópica, composta e atravessada por mais de uma perspectiva, como talvez toda perspectiva, quando tornada corpo (textual ou xamânico), seja marca de um encontro de perspectivas: as técnicas corporais dos xamãs, o parentesco que o constitui, as relações interespecíficas que compõem a sua experiência, todos esses outros e suas perspectivas dão corpo à perspectiva xamânica ${ }^{9}$; assim como o ponto de vista do autor, do narrador, dos personagens, mas também os paratextos, a edição, a crítica e as interpretações, todas essas perspectivas dão corpo ao texto, constituem a perspectiva de uma ficção literária. Ler o livro do mundo, fazer uma cosmografia, é, portanto, sempre ler os textos dos mundos, compor suas tessituras, desfazê-las (tirar consistência) e refazê-las (devolver consistência).

Recentemente, um integrante do partido pirada alemão afirmou, para justificar sua atuação política, que a internet é "o lugar onde vivemos", que "A web é o nosso campo de existência". De certa forma, ainda que provavelmente inconsciente, trata-se de uma belíssima definição da existência: o virtual seria o lugar onde a existência é possível no duplo sentido de que só naquele campo pode se dar a existência, e de que nele a existência se dá no modo da possibilidade. Mas isso implica dizer que sempre vivemos na internet - pois sempre vivemos no contato com mundos virtuais, ficcionais -, implica também que o que chamamos de mundo é apenas um caleidoscópio de perspectivas, sobreposição e entrecruzamento de mundos, uma teia ou hipertexto. Se as ciências humanas - as antropologias especulativas estão sendo economicamente contingenciadas, talvez seja porque elas revelem a contingência ecológica do mundo atual (enquanto única forma de habitar o cosmos), porque elas auxiliem na tentativa de colocar a imaginação no poder, potencializar a imaginação; em última instância, porque diante de um mundo que se tornou insustentável, elas podem apontar para a única alternativa realista: a demanda do impossível. Não só um outro mundo é possível como também um outro possível é mundo.

\section{REFERÊNCIAS}

CANDIDO, Antonio. Mundo desfeito e refeito. Cadernos de estudos linguísticos, 22, p. 41 45, 1992.

COETZEE, J.M. Elizabeth Costello: oito palestras. Tradução de José Rubens Siqueira. São Paulo: Companhia das Letras, 2004.

CERNICCHIARO, Ana. Perspectivismos. Sopro, 22, 2010. Disponível em: < http://culturaebarbarie.org/sopro/verbetes/perspectivismos.html >

\footnotetext{
${ }^{9}$ Devo essa idéia à leitura da tese de Nicole Soares-Pinto (2014), a quem sou grato pela interlocução.
} 
CHAKRABARTY, Dipesh. O clima da história: quatro teses. Tradução coordenada por Idelber Avelar. Sopro, 91. 2013. Disponível em: < http://culturaebarbarie.org/sopro/n91.html $>$

COSTA LIMA, Luiz. Trilogia do controle: O controle do imaginário, Sociedade e discurso ficcional, O fingidor e o censor. 3.ed. revista. Rio de Janeiro: Topbooks, 2007.

CRUTZEN, Paul J.; Stoermer, Eugene F. The Anthropocene. IGBP Newsletter, 41, 2000.

DANOWSKI, Déborah; Viveiros de Castro, Eduardo. Há mundo por vir? Ensaio sobre os medos e os fins. Desterro: Cultura e Barbárie; ISA, 2014.

HAGE, Ghassan. Critical anthropological thought and the radical political imaginary today. Critique of anthropology, 32(3). p. 285-308, 2012.

HELLER-ROAZEN, Daniel. Ecolalias. Tradução de Fábio Durão. Campinas: Ed. da UNICAMP, 2010.

JOYCE, James. Finn's Hotel. Tradução de Caetano W. Galindo. São Paulo: Companhia das Letra, 2014.

KUNDERA, Milan. A arte do romance. Tradução de Teresa Bulhões Carvalho da Fonseca. São Paulo: Companhia das Letras, 2009.

LÉVI-STRAUSS, Claude. Tristes trópicos. Tradução de Rosa Freire D’Aguiar. São Paulo: Companhia das Letras, 2006.

Introdução à obra de Marcel Mauss. In: Mauss, Marcel. Sociologia e antropologia. Tradução de Paulo Neves. São Paulo: Cosac Naify, 2003.

LEWIS, Simon L.; Maslin, Mark A. Defining the Anthropocene. Nature, 519, 2015.

LISPECTOR, Clarice. Felicidade clandestina. Rio de Janeiro: Rocco, 1998.

LUCIANO, Dana. The inhuman anthropocene. Publicado no blog Avidly, em 22/03/2015.

Disponível em: < http://avidly.lareviewofbooks.org/2015/03/22/the-inhuman-anthropocene/ >

LYOTARD, François. O pós-moderno. 3.ed. reimp. Tradução de Ricardo Corrêa Barbosa. Rio de Janeiro: José Olympio, 1990.

. O inumano: Considerações sobre o tempo. 2.ed. Tradução de Ana Cristina Seabra e Elisabete Alexandre. Lisboa: Estampa, 1997.

MANIGLIER, Patrice. Le tournant géologique de l'anthropologie. Comunicação apresentada no Colóquio Os Mil Nomes de Gaia. Rio de Janeiro. 2014. Disponível em < https://www.youtube.com/watch?v=gCJm1gBtnEQ >

MEINONG, Alexius. (2008) Teoría del objeto y Presentación personal. Tradução ao 
castelhano de Carola Pivetta; estudo introdutório de Emanuele Coccia. Buenos Aires: Miño y Dávila.

NODARI, Alexandre. O extra-terrestre e o extra-humano: notas sobre a revolta kósmica da criatura contra o criador. Landa, v.1, n.2. p.251-261, 2013.

I, oblique pronoun. New observations, 130. p.30-31, 2014.

ORTEGA Y GASSET, José. O homem e a gente: inter-comunicação humana. 2.ed. Tradução de J. Carlos Lisboa. Rio de Janeiro: Livro Ibero-Americano Ltda., 1973.

. Obras completas, tomo I (1902-1916). 7.ed. Madri: Revista de Occidente, 1966.

. A ideia do teatro. Tradução de J. Guinsburg. São Paulo: Perspectiva, 1991.

PINHEIRO, Tiago Guilherme. A literatura sob rasura: autonomia, neutralização e democracia em J.M. Coetzee e Roberto Bolaño. Tese de doutorado apresentada ao Programa de Pós-Graduação em Teoria Literária e Literatura Comparada da USP. 2014.

SAER, Juan José. O conceito de ficção. Tradução de Joca Wolff. Sopro, 15, p.1-4, 2009.

SOARES-PINTO, Nicole. Entre as teias do Marico: parentes e pajés djeoromitxi. Tese de doutorado apresentada ao Programa de Pós-Graduação em Antropologia Social da UnB. 2014.

STRATHERN, Marilyn. O gênero da dádiva: problemas com as mulheres e problemas com a sociedade na Melanésia. Tradução de André Villalobos. Campinas: Editora da Unicamp. 2006.

VIVEIROS DE CASTRO, Eduardo. Exchanging perspectives: the transformation of objects into subjects in Amerindian ontologies. Common knowledge, 10(3). P. 463-484, 2004.

. O nativo relativo. Mana, 8(1). P.113-148, 2002.

WAGNER, Roy. A invenção da cultura. Tradução de Marcela Coelho de Souza e Alexandre Morales. São Paulo: Cosac Naify, 2010. 